\title{
TERRITORIO HABITADO: EL CUERPO Y SUS MEMORIAS ${ }^{i}$
}

\author{
Luz Mary Uribe Balbín ${ }^{\text {ii }}$ \\ Arney Herrera ${ }^{\text {iii }}$ \\ Isabel Cristina Restrepo ${ }^{\text {iv }}$
}

\begin{abstract}
Resumen: El siguiente texto narra las experiencias en aula, desde una perspectiva de maestra participe y acompañante en el proceso del taller cuerpo y territorio como parte de la estrategia pedagógica, Laboratorio Territorios Aumentados desarrollada entre 2019 y 2020. El Laboratorio pretende abordar el concepto de territorio, desde sus relaciones con el cuerpo y el espacio para generar reflexiones de ciudadanía y paz en los estudiantes. El taller se da en tres momentos: mimesis; cuerpo paisaje, imagen del otro y, por último: dibujar la silueta del cuerpo; escribiendo en ella, los sueños, las heridas y las afectaciones del contexto de sus barrios. Dicho taller permite un encuentro con el otro, lo diverso, el trabajo en equipo y reconocimiento del cuerpo como el primer territorio habitado.
\end{abstract}

Palabras Claves: Cuerpo; Espacio; Creación; Narración de experiencia en aula.

\section{TERRITÓRIO HABITADO: O CORPO E SUAS MEMÓRIAS}

Resumo: O texto a seguir narra as vivências em sala de aula, na perspectiva do professor, participa e acompanha o processo de oficina corpo e território como parte da estratégia pedagógica, Laboratório Territórios Aumentados desenvolvido entre 2019 e 2020. O Laboratório pretende abordar o conceito de território, a partir de suas relações com o corpo e o espaço para gerar reflexões de cidadania e paz nos alunos. O workshop acontece em três momentos: mimese; paisagem corporal, imagem do outro e, por fim: desenho da silhueta do corpo; escrevendo nele, os sonhos, as feridas e os efeitos do contexto de seus bairros. Esta oficina permite o encontro com o outro, o diverso, o trabalho em equipa e o reconhecimento do corpo como primeiro território habitado.

Palavras-chave: Corpo; Espaço; Criação; Narração de experiência em sala de aula

\section{Mimesis: Cuerpo y espacio}

\begin{abstract}
Situarse ante la educación como experiencia, significa centrarse en las cualidades de lo que se vive: acontecimientos que están situados en el tiempo, que se viven temporalmente, que están localizados en momentos, lugares, relaciones; lo que se vive, además, sucede siempre en un cuerpo sexuado... donde tu ser intimo está implicado...sentimientos, emociones, razón. (CONTRERAS y PÉREZ, 2013, p. 23).

El espacio constituye un elemento esencial de la existencia humana, en la medida que trata cuestiones tan fundamentales como la dimensión del ser, la ubicación geográfica o el posicionamiento en el mundo de los objetos o de la sociedad misma. (RAMÍREZ y LÓPEZ, 2015, p. 17)
\end{abstract}


Es jueves, estamos esperando al compañero Arney, estudiantes de licenciatura en educación: en artes plásticas, para orientar la actividad de aula, se tiene los equipos disponibles, computador, video beam, cables, todo está listo para la sesión. Él entra, saluda con la calidez de su sonrisa habitual, descarga su pesada maleta. Todos esperamos a la expectativa y se escucha, a distintas voces, la pregunta habitual: ¿Qué vamos a hacer profe? La respuesta aparece proyectada sobre el blanco del tablero: el cuerpo y el paisaje, seguido de una presentación audiovisual donde aparecen unas series de imágenes silenciosas pero potentes que acompañadas de la voz tranquila del profe van señalando la ruta. Aparece el cuerpo en mímesis con los objetos, aparece el cuerpo habitando espacios, aparecen las instrucciones básicas para que los chicos hagan registros propios, registros de ellos mismos interactuando con sus cuerpos, con los otros, con su entorno para crear representaciones en las cuales reconocer, reconocerse. Las chicas y los chicos están expectantes, curiosos y deseosos de ponerse en movimiento, en acción. Entre los vaivenes de sus voces a destiempo, se escucha en la voz del compañero Arney, las indicaciones más precisas para hacer las tres actividades acordes con lo expuesto, se organiza el aula para abrir espacio en el centro, se corren las sillas, unos se sientan, otros se quedan de pie, y después del ruido en el movimiento emerge un silencio expectante, todos están a la espera de que sigue después. Se recapitula lo que se va a hacer, se trabajara con el cuerpo, se imitaran figuras, para ello proyecta de nuevo la presentación en PowerPoint, aparecen figuras simples que confrontan e incomodan, un cuadrado, una equis, una silla, una cruz, una casa, ahora son modelos a imitar, a seguir, o más bien a representar con los propios cuerpos.

Entre risas nerviosas comienza la acción, se observa temor, corazones acelerados, cuerpos sudorosos, aparecer las primeras mimesis en el aula bajo la instrucción clara de la imagen proyectada en pantalla. Luego, el temor va cediendo, los chicos y las chicas van tomando confianza, preguntan ¿qué más hacer? Las imágenes proyectadas se vuelven insuficientes, emergen nuevas mímesis, ahora guiadas por la tridimensionalidad del espacio. Algunas en el piso, otras encima de las sillas y mesas, otras junto a las paredes. Hay intercambio de roles, me convocan, ya no soy maestra, soy una compañera requerida en el juego creativo. De repente se corta la acción, -Chicos vamos a continuar en las zonas verdes y patios-. Todos se ponen felices, ;por fin! Libres, --esperen, ahora vamos a mimetizarnos con los objetos que encontremos en el exterior- señala Arney. Por favor, tomen sus cámaras, en equipos de 6 para el registro de la experiencia. --. Salieron a toda prisa, por no decir corriendo. Los patios, pasillos, árboles, cafetería, motos, rejas, sillas de la institución y, hasta el mismo sol y el infinito del espacio exterior, se convirtieron en objetos para la interacción creativa con nuestros cuerpos. 
Luces, sombras, variedad de verdes, sonidos de hojas secas, olores a humedad y a hierba fresca se mezclaron con los cuerpos, con nuestros cuerpos, no importó deteriorar o ensuciar los uniformes, fuimos arte y parte del paisaje.

Dentro de las muchas representaciones está la de Daniela y Sara Luna ensamblando sus piernas para enmarcar la frondosidad de un árbol, la de Mariana Viva reposando extendida en una banca horizontal, la de un estudiante anónimo en la fotografía cuyas manos tratan de atrapar el sol. Todas estas colaboraciones creativas, entre cuerpos y espacios, quedan reflejadas en fotografías realizadas por nosotros mismos, fotografías de un momento transitorio que nos permitió salir de las miradas cotidianas, para re-conocernos en el aquí y el ahora, ese que Walter Benjamín señala para el aura de la experiencia artística. Mientras tanto, yo, me integro al juego y poso mi cabeza en un árbol en un abrazo invertido dirigiendo mi mirada hacia el infinito. Llega el descanso, el tiempo no fue suficiente, nunca lo es, todos queríamos seguir en la actividad, correteando lúdica y creativamente por cada rincón de la institución.

\section{La imagen del otro: el encuentro con la mirada}

El cuerpo es, así, el lugar primero, el lugar -fundamento de "habitar" ...Este cuerpo-espacio es también, e inmediatamente, el cuerpo en el espacio-el espacio tal como es percibido y experimentado por cada uno a partir del lugar propio del cuerpo-. (DELORY-MOMBEGER, 2015, p. 32, 33).

Hay algo oculto en cada cosa que ves. Lo que vez lo vez siempre para ver otra cosa. (PESSOA, 1984, p. 133)

Es jueves por la tarde, de nuevo en el aula esperando al compañero Arney, es la cita de cada semana. Como es habitual al llegar descarga su maleta sobre la mesa, y con prontitud saca los implementos para la clase, esos que servirán como dispositivos de creación. Esta vez, nos invita a sentarnos, uno frente a otro, una nueva disposición para el autoconocimiento y el intercambio con el otro. Nos invita a organizar el aula en un semi cuadrado y a trabajar con papel en blanco, lápiz, borrador. Esta vez propone un acercamiento distinto al cuerpo desde la mirada del rostro: La imagen del otro. Arney explica con detalle la actividad. Tarea compleja esta de traducir lo observado en trazos a blanco y negro sobre el espacio delimitado en un formato de una hoja tamaño carta u oficio, o del cuaderno de dibujo.

Todos nos mirábamos con incertidumbre, con deseos de salir corriendo — ¿cómo empezamos?, ¿cómo lo hacemos? - Las palabras de Arney proponen: -hagan el ejercicio de mirarse al rostro entre sí, guardar en la memoria las facciones y líneas de expresión y empiecen Revista Interinstitucional Artes de Educar. Rio de Janeiro, V. 7, N. 1 - pág. 597-609 janeiro-abril de 2021: "Pedagogias Vitais: Corpo, Desejo e Educação" DOI: 10.12957/riae.2021.55457 
a plasmarlas en el papel- Emergen pequeños murmullos, miradas esquivas, risas nerviosas, en medio de un silencio prolongado. ¿Quién empieza?, ¿profe necesitamos reglas? ¿Podemos borrar?, preguntas que rompen el hielo y dan comienzo a los primeros pequeños trazos de algunos, mientras otros aún intentan acomodarse en las sillas, jugueteando con los lápices en sus manos sudorosas. Yo me encontraba dentro del segundo grupo, me sentía temerosa, confrontada en lo más íntimo por esta actividad inédita, en mis cincuenta y un años de vida, esta era la primera vez que estaba sentaba frente a la mirada del otro, desnuda ante mis miedos; era también la primera vez, que me enfrentaba a dibujar al otro, a representar el contorno del rostro para traducir un territorio habitado que diera cuenta tal vez, de esas facciones tangibles y de aquellas intangibles que configuran su esencia, o por lo menos, esa que logró captar desde mi percepción.

Dibujar el rostro del otro, la imagen del cuerpo me horrorizaba... Ahora ya todos hemos empezado a trazar las líneas que darán forma a retratos en blanco y negro de sus rostros que, aunque cercanos no hemos visto desde la profundidad del ser. Nuestras miradas se cruzaban, flotaban sonrisas y pequeñas carcajadas ruidosas irrumpían a veces en la concentración de la acción, las palabras se ahogaban en el abismo de la incomodidad de algunos, creo, pues incomodidad era lo que yo estaba sintiendo. Los chicos y las chicas agrupados por afinidades afectivas asumen esta sesión de distintas maneras. Algunos tomaron la actividad como un juego jocoso y frívolo: sección de chistes, conversación de hechos cotidianos, coqueteos entre amigas y amigos. Otros asumieron la actividad como un juego lúdico y creativo, es decir con todo el rigor, se sumergieron en una experiencia expresiva íntima configurada por el movimiento de la mano sobre el papel, guiados por una atención minuciosa a detalles inexplorados del otro y de sí mismos.

Yo me hice con un chico que no tenía compañía. Brayan, cercano y afable, de intervenciones precisas, a quien conocía desde hace casi dos años y quien, por primera vez, tenía la posibilidad de observar de cerca, podía ver en primer plano sus reservas, silencios y ternura enmarcadas en facciones bien definidas. Por segundos, había ausencia de palabras entre ambos, luego los trazos de quien traduce la mirada dejaban sus huellas en el papel, irrumpen los primeros esbozos gráficos tímidos y cortados. De pronto se escuchan los pasos de quienes registran la acción, en este caso es estudiante externo acompañante del proceso, quien con su mirada y sus cámara captura los avances de la actividad, al verlo, nuestra primera reacción es cubrir el dibujo con las manos y tan solo con timidez y lentitud damos cabida a su mirada, así como a la de su cámara fotográfica, ese dispositivo tecnológico que captaría el momento y facilitaría otras miradas, soy observada, seré observada por muchos otros después. Pasados Revista Interinstitucional Artes de Educar. Rio de Janeiro, V. 7, N. 1 - pág. 597-609 janeiro-abril de 2021: "Pedagogias Vitais: Corpo, Desejo e Educação" DOI: 10.12957/riae.2021.55457 
unos minutos de actividad creadora muchos dejaron sus sillas, se estiraron en el piso, se ubicaron en nuevas posturas buscando cierta comodidad y un mejor ángulo para dibujar al otro, tal vez para evitar la mirada frontal directa, tan confrontadora e implacable.

En general, sorprenden los resultados, hubo gran maestría y destrezas desconocidas en muchos detalles sutiles, líneas definidas, otras entrecortadas, sombras contrastadas, claros oscuros moldearon facciones, el texto aparece en algunas infografías que acompañan a las imágenes dibujadas del otro. El acto de observar, de memorizar las expresiones del compañero y luego de delinear en el papel, produce resultados contundentes, emergen distintos estilos gráficos desde la representación realista hasta los toques caricaturescos de influencia anime. Mi dibujo, con líneas gruesas, plasma cierta dureza en las facciones traducidas del rostro del estudiante, él no es así, me pregunto si lo que plantee fue más bien la dureza personal propia del miedo que siento a dibujar el cuerpo, la figura humana, negado en la memoria de la infancia y en el ruido de las aulas.

Los jóvenes disfrutaron la actividad y la interacción con el otro, observaban cada dibujo a manera de jueces, o más bien críticos de arte, decían --este dibujo es igual al modelo, este no se parece en nada - así sucesivamente caminaban en círculo en el aula. El tiempo expuesto ante la mirada del otro fue angustiante para mí y no sentí el disfrute que aparentemente vi reflejado en otros rostros, en otros retratos.

\section{El cuerpo y sus memorias}

El cuerpo es el lugar donde se inscribe cada historia singular, el lugar donde sentimientos y pensamientos se manifiestan, en latidos, en palabras, en imágenes, en nudos que oprimen o brisa que orea el alma. (CONTRERAS y PÉREZ, 2013, p. 31)

Cuando algún rastro nos conmueve instantáneamente en lo físico, lo psicológico y lo emocional, es porque se ha revelado ante nosotros como huella. (CRIOLLO, 2010, p. 46).

La llegada de Arney viene acompañada de una nueva invitación creativa. Esta vez, teníamos el compromiso de traer pliegos de cartulina o papel en formatos grandes. Sin embargo, esperábamos las acostumbradas instrucciones brindadas a través de su voz. La invitación fue precisada: Dibujar la silueta del compañero, dejar que el compañero dibuje la propia, para luego representar las heridas propias, esas que dibujan nuestra piel, tejen nuestro ser, construyendo nuestra identidad. Esto a partir de narraciones autobiográficas, representadas de forma gráfica 
y escrita, en palabras e imágenes libres de aquello con lo cual podríamos responder las siguientes preguntas: ¿Qué cicatrices tiene cada uno? ¿Cuál es la historia de cada cicatriz? ¿Cómo describe cada uno su cuerpo? ¿Cuáles son sus sueños? En particular, Arney invita a todos a conformar parejas para que cada uno tuviese alguien que dibujara su silueta, y posterior a esto dar inicio a un ejercicio de introspección individual, personal e íntima a partir del dibujo de su silueta. De nuevo, después de que el guion para la actividad ha sido descrito y se propone dar inicio se observa cierto nerviosismo en el ambiente, tal vez producto de la timidez, la emoción o la inquietud. Se escuchó una voz fuerte un -Nooooo, proooofe- de parte de algunos que inventaban miles de excusas para no dar inicio a la actividad: que somos muy feos, que el espacio no es cómodo, que no saben dibujar, pretextos para evadir el tener que reconocerse, hablar de sí.

Mientras que las chicas y los chicos más entusiasmados pusieron el papel en el piso, empezaron a unirlo acorde a su estatura, discutían sobre quién sería el primero o la primera para extenderse sobre el papel para que el compañero lo delineara, por fin deciden quien dibujará primero y quién será el modelado, después intercambiaron roles, para posteriormente concentrarse cada uno en su creación. Ante los primeros resultados emergen diversas reacciones, algunas de negación, que la calidad de los trazos no era la indicada, que el dibujo estaba muy feo, que mejor lo hacían en la casa, una y mil excusas para no verse delineado o delineada en el papel, para evitar ser observado por los otros compañeros, para postergar responder a las preguntas planteadas sobre la memoria de sus pieles, dos semanas pasaron con sus siluetas sin traer resultados al aula, sin terminar, sin definir aún qué escribir.

Otras reacciones en cambio fueron bastante creativas y espontáneas, reflejaban una apropiación clara de la actividad como un medio de expresión libre autoconocimiento, lo que se veía expresado en el detalle de los elementos, en el vestido de la silueta, en la decoración acorde a sus gustos; sus siluetas exponían gráficamente cadenas, manillas, y camisetas, detalles significativos, a veces regalados por mamá, papá, abuelos, hermanos, amigos, o simplemente comprado por ellos mismos. Estos últimos atentos al proceso, mostraban orgullosos sus figuras con creativas decoraciones, con figuras de su gusto corazones, flores, balones de fútbol, los símbolos de sus equipos favoritos e incluso con tranquilidad mostraban los vestigios de episodios dolorosos. De esta forma, las siluetas exponían marcas y vestigios, algunos dolorosos y otros de alegría, algunas eran cicatrices por accidente como la cicatriz en la rodilla de Juan Diego López cuando se cayó en la bicicleta, otros castigos por travesuras de infancia como el dibujo de la chancla en la nalga de Valery Lujan. Sus siluetas también revelan las cicatrices de los territorios habitados; en la silueta a la altura de la nariz; representan el humo de sustancias Revista Interinstitucional Artes de Educar. Rio de Janeiro, V. 7, N. 1 - pág. 597-609 janeiro-abril de 2021: "Pedagogias Vitais: Corpo, Desejo e Educação" DOI: 10.12957/riae.2021.55457 
psicoactivas que los incómoda en su cotidianidad, en los oídos expresan el ruido de la música de las calles donde viven, en la cabeza expresan los dolores de cabeza por el ruido excesivo.

En general, sus siluetas muestran las huellas de sus propias experiencias, de aquellas marcadas por sus seres más cercanos, por personas externas pero cercanas a la cotidianidad de los sus tránsitos cotidianos en el barrio, de sus temores más íntimos, así como aquellos generados antes estándares externos o ideales de belleza sobre la altura, el color de la piel, el peso corporal, o el tipo de cabello. Las siluetas fueron pues, un medio, para pensar en sus cuerpos, en sus intimidades, en sus memorias y sus experiencias vividas y registradas en su piel.

Las siguientes imágenes registradas por los estudiantes del grado $7^{\circ} .2$, muestran la relación del cuerpo con el espacio en el aula y fuera de ella. Institución Educativa Fe y Alegría la Cima, Medellín, Colombia.

Comienzo a vislumbrar cómo el cuerpo y el tiempo constantemente entran en juego con el espacio y los objetos; cómo la huella corporal y su "duración" se presentan como potentes transformadores y creadores de memoria. (CRIOLLO, 2010, p. 19)

Figuras 1 y 2: Estudiantes Grupo 7.2. Figuras con el cuerpo, una (X) y una casa.

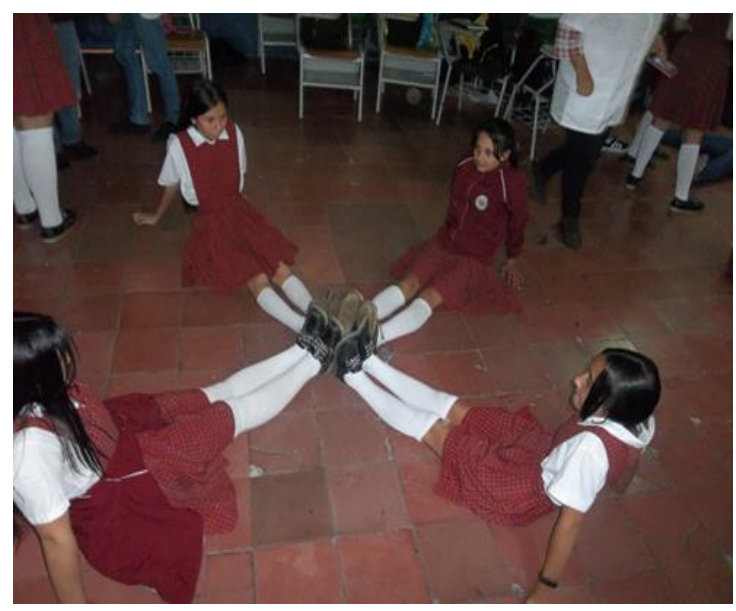




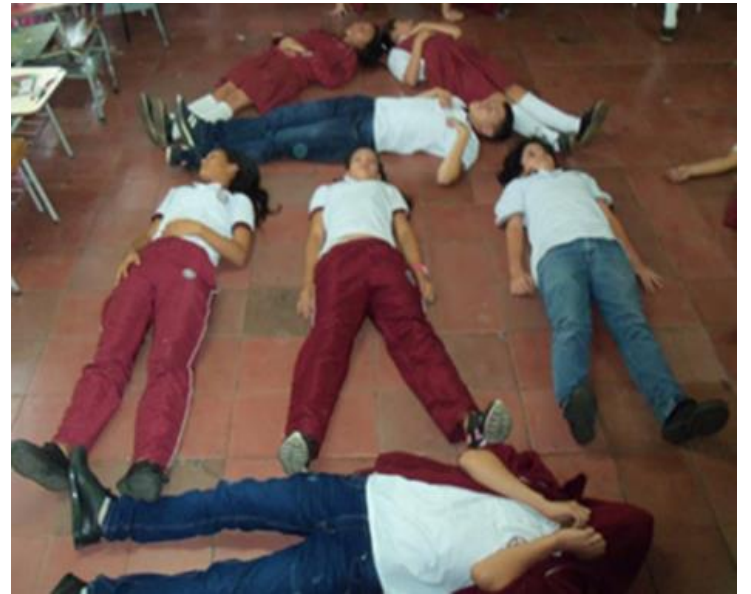

Figuras 3 y 4: Estudiantes Grupo 7.2. Mimesis: silla- arbol
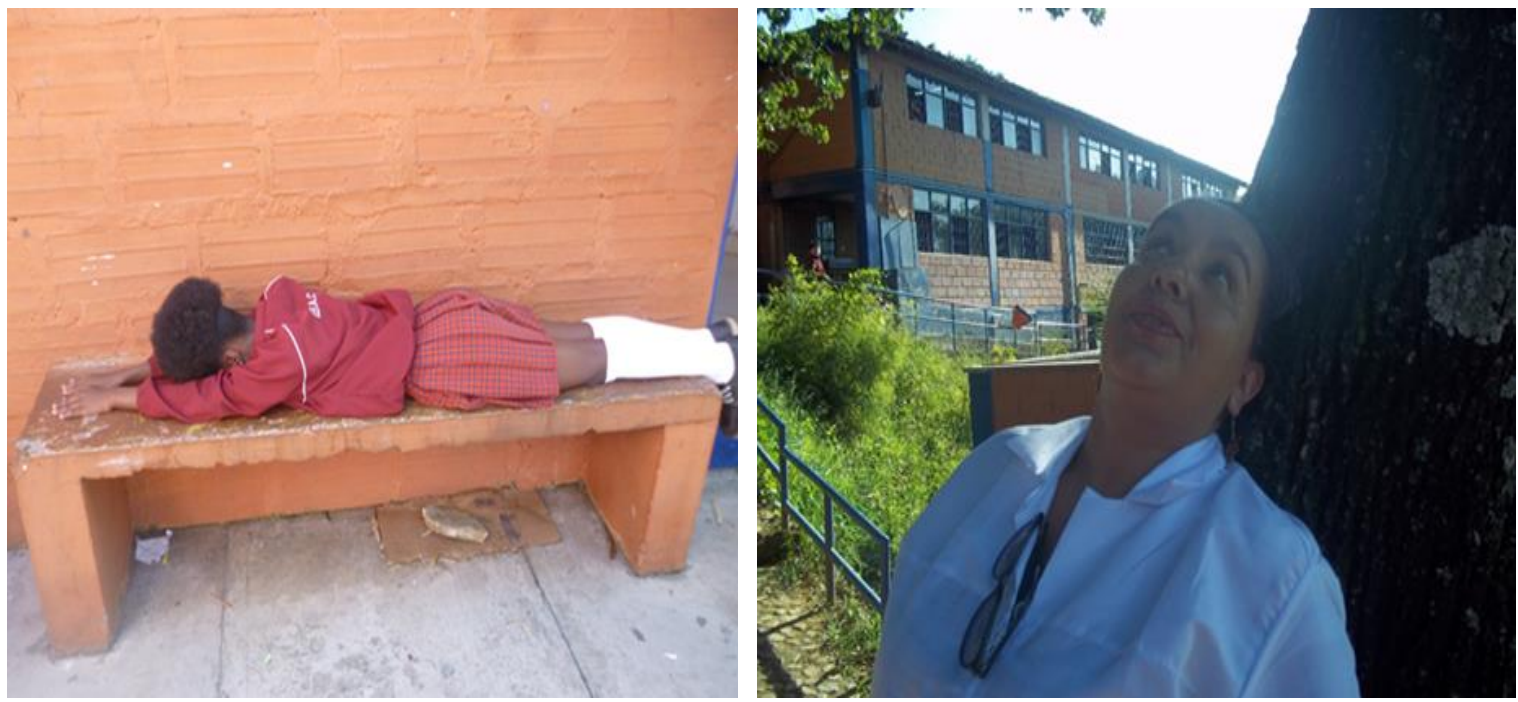

Figuras 5 y 6: Estudiantes Grupo 7.2. Mimesis: cuerpo - árboles
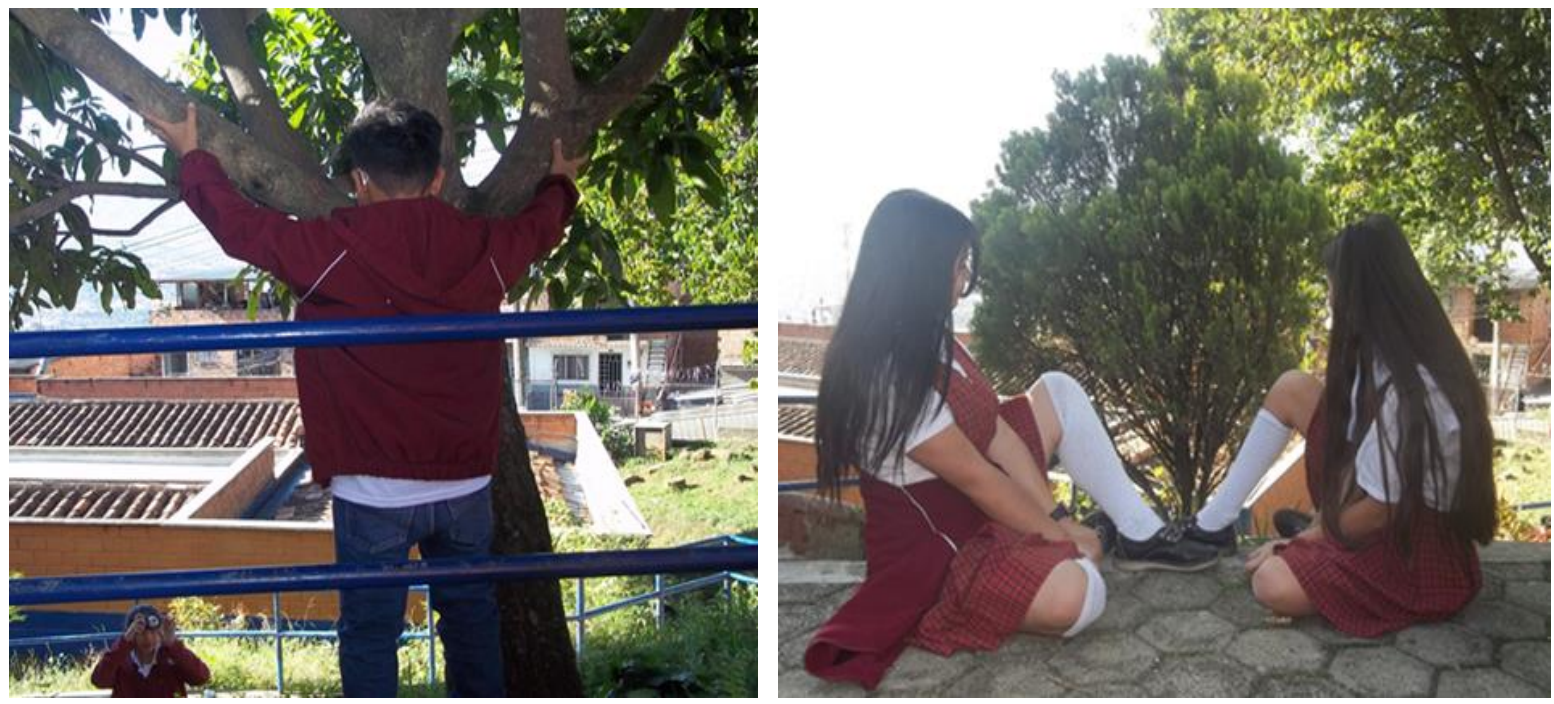

Figuras 7 y 8: Estudiantes Grupo 7.2. Mimesis: manos - naturaleza

Revista Interinstitucional Artes de Educar. Rio de Janeiro, V. 7, N. 1 - pág. 597-609 janeiro-abril de 2021: "Pedagogias Vitais: Corpo, Desejo e Educação" DOI: 10.12957/riae.2021.55457 

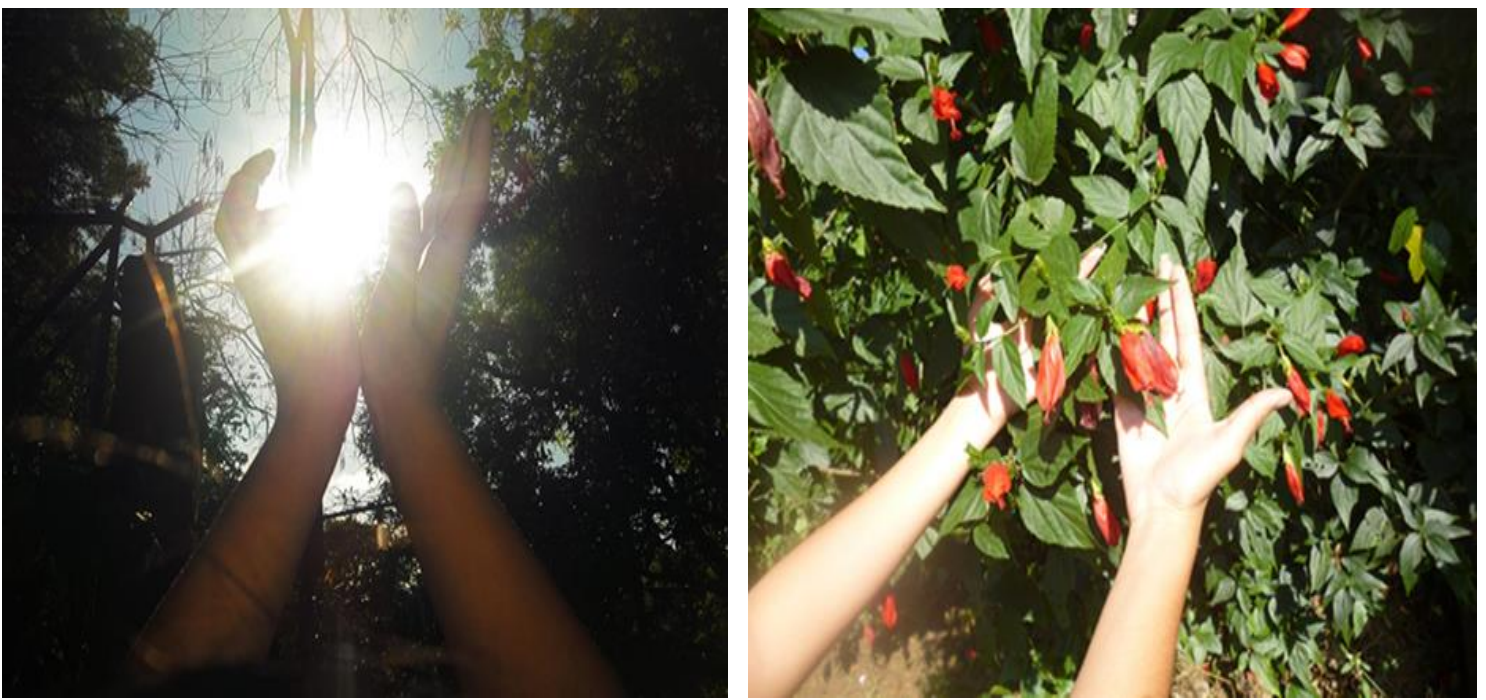

Las siguientes imágenes registradas por Arney Herrera, en la actividad, dibujar el rostro en el encuentro con la mirada del otro.

La experiencia del tú es pues siempre la experiencia de mi relación contigo. Esa relación, que es a la vez una relación de autoconocimiento, y de conocimiento de la relación en sí. (CONTRERAS y PÉREZ, 2013, p. 30).

Figuras 9 y 10: Arney Herrera. Dibujos de Nicolas Castrillón y Manuela González
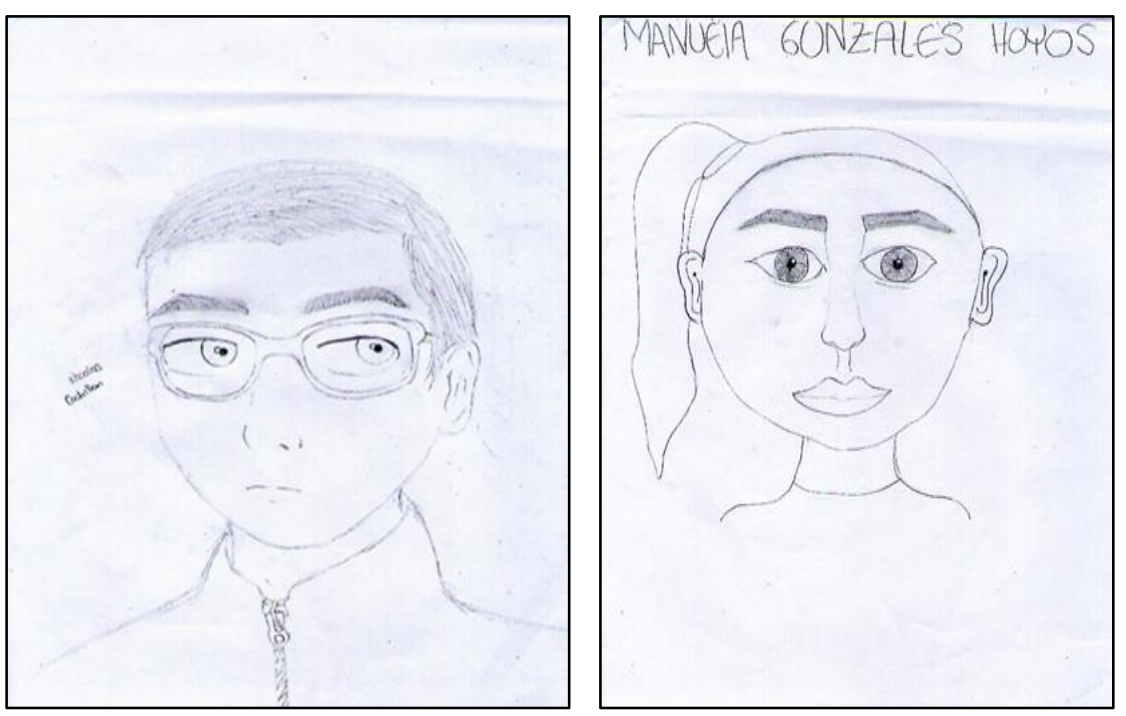

Figuras 11 y 12: Arney Herrera. Dibujos de Mariana Vivas y Valeria Martínez. 

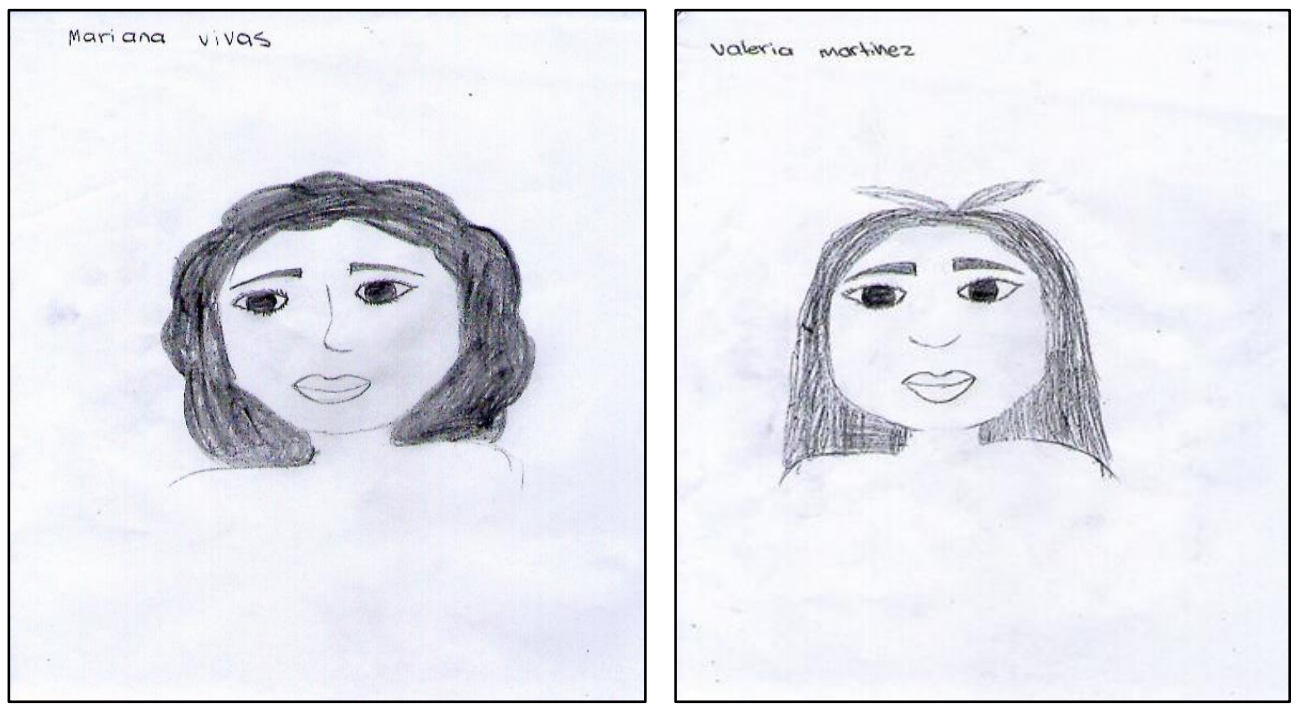

Figuras 13 y 14: Arney Herrera. Dibujos de María Camila Padierna y Alexander Sotelo.
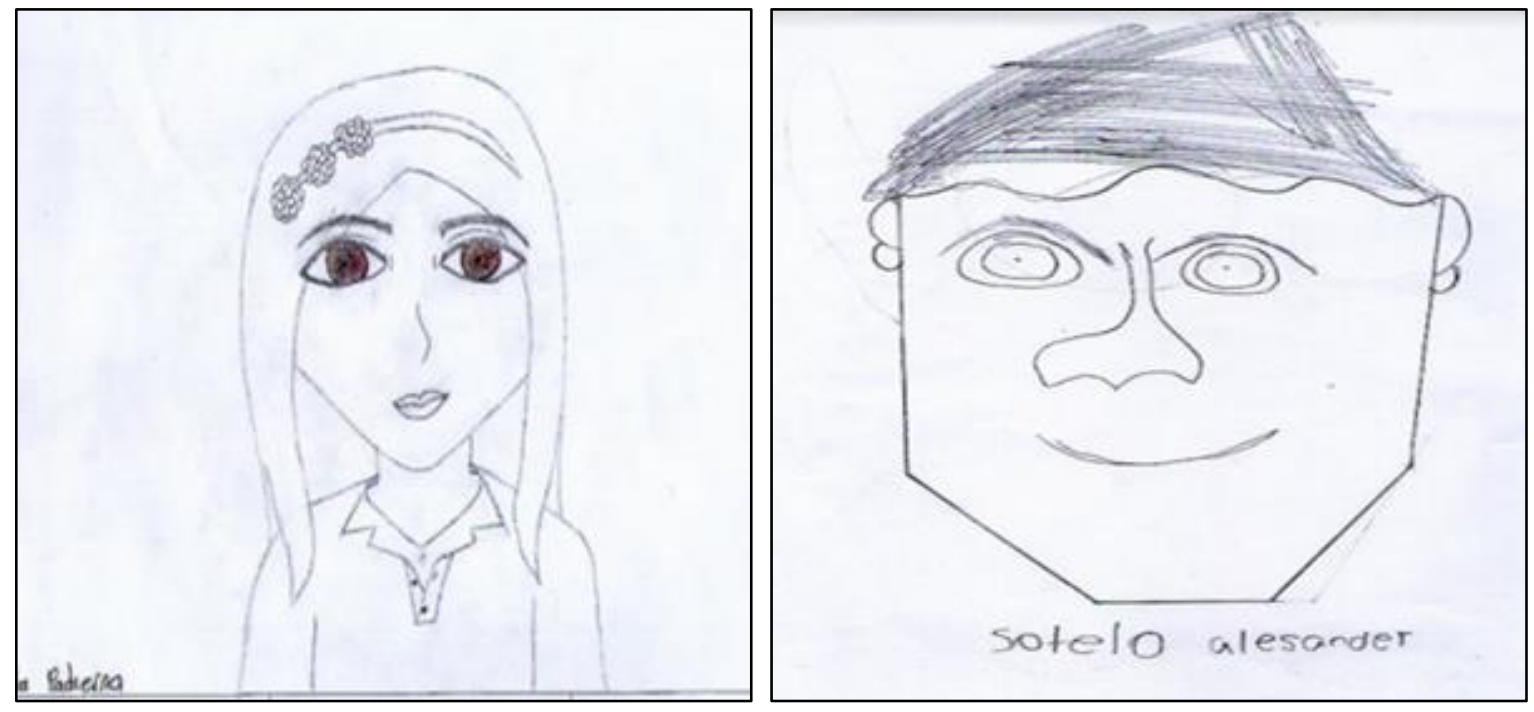

Figuras 15 y 16: Arney Herrera. Dibujos Arturo Villa y Johan Ríos

Revista Interinstitucional Artes de Educar. Rio de Janeiro, V. 7, N. 1 - pág. 597-609 janeiro-abril de 2021: "Pedagogias Vitais: Corpo, Desejo e Educação" DOI: 10.12957/riae.2021.55457 

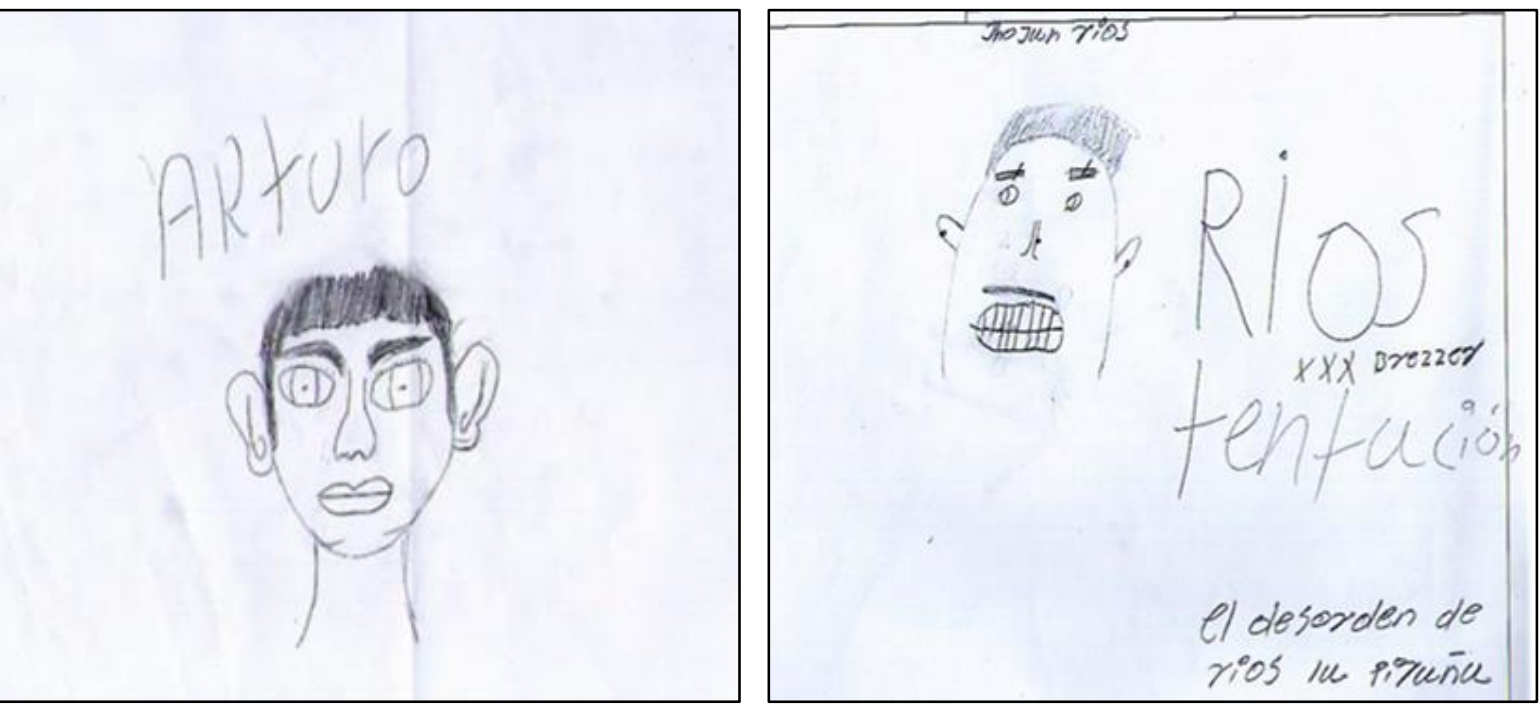

En las siguientes imágenes registradas se muestra la relación íntima entre el cuerpo, su representación creativa y sus cicatrices.

Una experiencia lo es en la medida en que no te deja indiferente: te implica, te afecta, te marca, te deja huella. La experiencia no es algo que "sucede", sino algo que se tiene. (CONTRERAS y PÉREZ, 2013, p. 24)

Figuras 17 y 18: Luz Mary Uribe. En intimidad con mi silueta
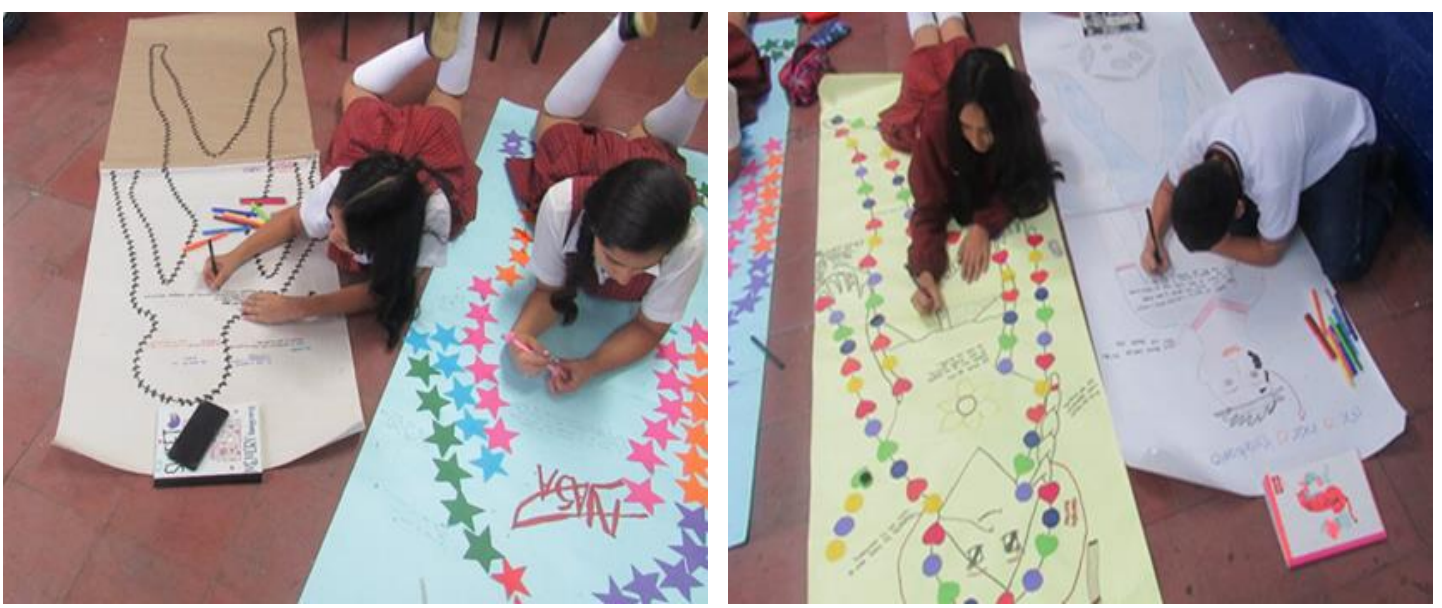

Figuras 19 y 20: Luz Mary Uribe: En intimidad con mi silueta 

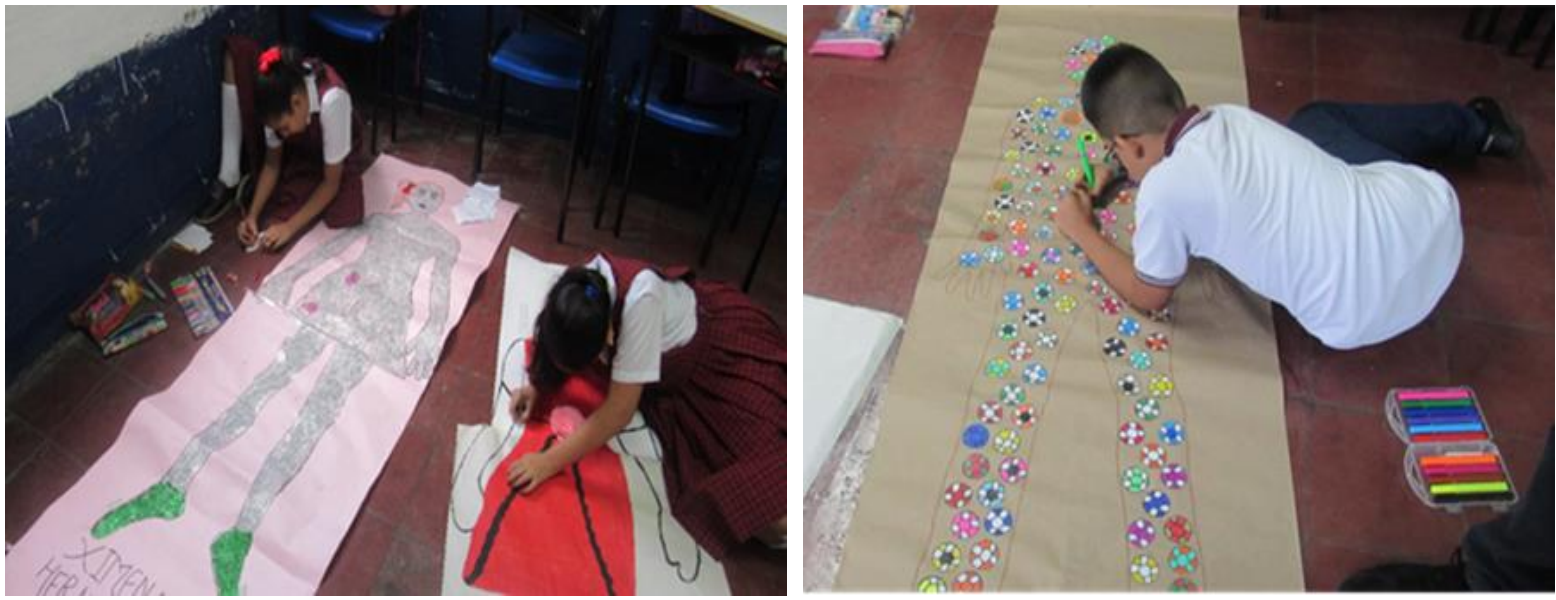

Figuras 21 y 22: Luz Mary Uribe: siluetas de loValery Lujan, Santiago García, Arturo Villa y Valery González
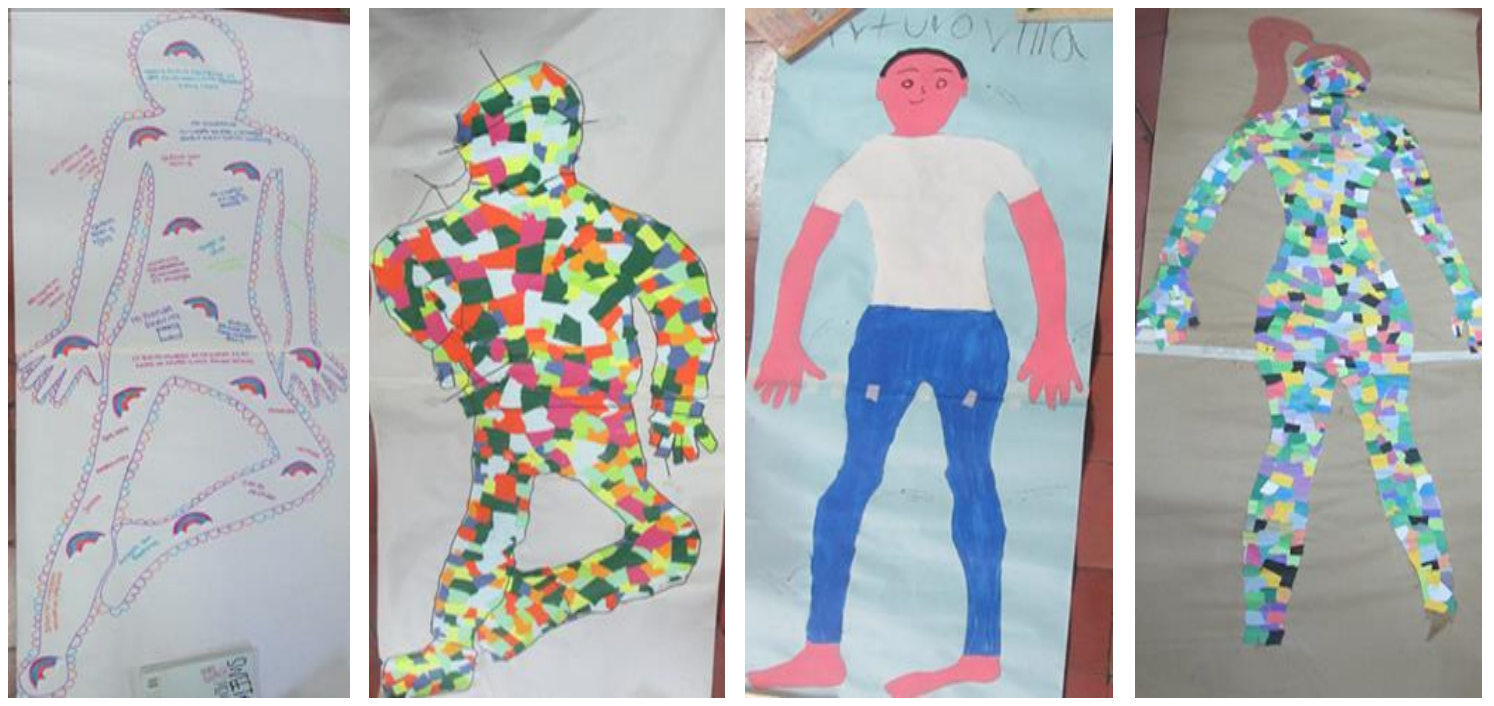

\section{REFERENCIA}

CONTRERAS, J y PÉREZ de Lara, N. Investigar la Experiencia educativa. Madrid: Morata, 2013.

CRIOLLO C, L N. Cuerpo expandido. Bogotá: Pontificia Universidad Javeriana, 2010.

DOLORY, M. C. La Condición biográfica: Ensayos sobre el relato de sí en la modernidad avanzada. Medellín: Universidad de Antioquia, 2015.

RAMÍREZ V, B.R.; LÓPEZ Levi L. Espacio, paisaje, región, Territorio y lugar: la diversidad en el momento contemporáneo. México: UNAM, Instituto de Geografía: AUM, Xochimilco, 2015 .

Sistematización de las experiencias en el aula en: http://www.titeresenpantalla.org/

Revista Interinstitucional Artes de Educar. Rio de Janeiro, V. 7, N. 1 - pág. 597-609 janeiro-abril de 2021: "Pedagogias Vitais: Corpo, Desejo e Educação" DOI: 10.12957/riae.2021.55457 
${ }^{\text {i }}$ El presente texto narrativo da cuenta de la experiencia en el aula del taller Cuerpo y Territorio como parte de la estrategia pedagógica, Laboratorio Territorios Aumentados desarrollada entre 2019 y 2020 como parte de la investigación monográfica titulada Propuesta pedagógica para experiencias de co-creación artística, espacial, territorial y de formación ciudadana a través de narrativas de multimedia con los estudiantes del grado séptimo de la Ins. Educ. Fe y Alegría la Cima y desarrollada por el estudiante Arney Herrera de Licenciatura en Artes del Departamento de Artes Visuales de la Facultad de Artes de la Universidad de Antioquia. Este proceso estuvo acompañado por la investigadora y docentes institucional Luz Mary Uribe Balbín y con la asesoría de la profesora Isabel Cristina Restrepo. Territorios Aumentados se enmarca a su vez en la investigación Laboratorio de territorio, ciudadanía y paz, del Instituto de Estudios Regionales: INER y el grupo de investigación Hipertrópico: Convergencia entre arte y tecnología de la Facultad de Artes de la Universidad de Antioquia. Territorios aumentados se implementó en la I.E Fe y Alegría la Cima de Medellín, donde participaron 36 estudiantes del grado $7^{\circ} 2$ de la Institución. El Laboratorio se configura como un espacio que pretende abordar el concepto de territorio, desde sus relaciones con el cuerpo y el espacio para fomentar reflexiones de ciudadanía y paz en los estudiantes. El concepto de territorio se aborda didácticamente desde la sensibilidad, con el acontecer diario de los estudiantes y sus problemáticas sociales, la apreciación estética de los espacios y otras formas de comunicar las ideas que permite la convergencia entre educación arte y tecnología a través de la producción de diversas narrativas multimedia. El Laboratorio se da en una secuencia didáctica dividida en tres talleres denominados: Cartografías Unidas; Cuerpo y Territorio; y Narrativas Territoriales.

ii Maestra de la Institución Educativa Fe y Alegría la Cima, adscrita a la secretaría de educación de Medellín; magíster en Ciencias Sociales de la Universidad de Antioquia y estudiante de doctorado en educación: Programa específico en formación en investigación narrativa y autobiográfica de la Universidad del Rosario Argentina. Correo electrónico: madremonte7@gmail.com. ORCID iD: https://orcid.org/0000-0001-6853-6918.

iii Estudiante de Licenciatura en Educación: Artes Plásticas de la Universidad de Antioquia y estudiante en formación del grupo de Investigación Hipertrópico de la facultad de Artes. Correo electrónico: arney.herrera@udea.edu.co. ORCID iD: https://orcid.org/0000-0001-6453-9038.

iv Profesora de la Universidad de Antioquia, adscrita al Departamento de Artes Visuales y coordinadora del grupo de Investigación Hipertrópico de la Facultad de Artes; Doctora en Artes de la Universidad de Antioquia. Correo electrónico: cristina.restrepo@ udea.edu.co. ORCID iD: https://orcid.org/0000-0002-8235-3525. 